\title{
The Effect of Green Tea Extract on Submandibular Salivary Gland of Methotrexate Treated Albino Rats: Immunohistochemical Study
}

Ali Sultan Al-Refai ${ }^{1}$, Ameera Kamal Khaleel ${ }^{2^{*}}$ and Shaheen Ali ${ }^{2^{*}}$

${ }^{1}$ Anatomy Branch - Department of Oral \& Maxillofacial Surgery, College of Dentistry, Hawler Medical University, Erbil, Kurdistan Region of Iraq ${ }^{2}$ Department of Oral Diagnosis, College of Dentistry, Hawler Medical University, Erbil, Kurdistan Region of Iraq

\begin{abstract}
Background and objectives: Methotrexate (MTX) had been used for many years and complications usually encountered during treatment especially in cancer patients. The aim of the present study was to determine the preventive and early-stage anti cytotoxic effects of green tea on the histology of the submandibular gland of rats treated by high single dose of methotrexate.

Materials and methods: The study included 36 Albino rats. Twelve animals were used in the pilot study to find the maximum toxic dose, and the other twenty four were divided into four groups, vehicle treated control group, green tea extract treated control group ( $40 \mathrm{mg} / \mathrm{kg} /$ day), methotrexate treated group $(80 \mathrm{mg} / \mathrm{kg}$ ), and methotrexate and green tea extract treated group. Submandibular glands excisions were then performed. Histopathological examination was performed with hematoxylin-eosin, Masson's trichrome, and PAS stains. Cell proliferation was examined using the Ki-67 antibody and anti apoptotic effect was determined based on Bcl-2 staining.
\end{abstract}

Results: In the methotrexate and green tea extract treated group a non significant difference in the Ki-67 expression $(p>0.01)$ and a significant increase in Bcl-2 expression $(p<0.01)$ were seen in comparison with the methotrexate treated group.

Conclusion: Green tea aqueous extract at a concentration of $40 \mathrm{mg} / \mathrm{kg} / \mathrm{day}$ produced a protection against methotrexate induced cytotoxicity in rat submandibular gland by increasing the expression of Bcl-2.

Keywords: Methotrexate; Salivary gland; Chemotherapy; Green tea

\section{Introduction}

Chemotherapy is one of the most widely used interventions for treatment of cancer. The cytotoxic effect of cancer chemotherapy is not selective for cancer cells, it also affects the normal tissues, the amount of the damage and its severity is based on the type, amount and duration of drug used to treat the disease [1]. Methotrexate (MTX), a folic acid antagonist, is widely preferred as a cytotoxic chemotherapeutic agent in the treatment of malignancies and some autoimmune diseases, but the efficacy is limited due to its side effects [2]. Several studies found that both folate and folinic acid (leucovorin) reduce methotrexate toxicity, but there is some evidence that folic acid supplements could reduce methotrexate efficacy in the treatment of cancer [3].

It was revealed that the systemic oxidative stress is an important factors background of the MTX induced toxicity. MTX causes differential toxic effects on lipid peroxidation by significant reduction in glutathione levels leads to a reduction of effectiveness of the antioxidant enzyme defense system, sensitizing the cells to reactive oxygen species. Therefore, the antioxidants protect against oxidative stress and prevent damage to cells [4].

Some natural products, such as green tea is demonstrated to have a protective role against oxidative stress $[5,6]$. Green tea from the plant Camellia Sinensis is rich in antioxidant polyphenolic flavonoids $[7,8]$. Epigallocatechin gallate (EGCG), a green tea polyphenol, possesses potent antioxidant, anti-apoptotic, anti-inflammatory, and auto antigen-inhibitory properties. It is therefore extensively studied for probable health benefits against oxidative stress-related diseases, and could normalize abnormal cell proliferation of the salivary gland [9].

The submandibular salivary gland is considered the second largest salivary gland, it produces about $60 \%$ of saliva. Saliva has an important role to keep healthy conditions of the oral cavity. Thus, it was possible that patients with cancer therapy or radiation therapy could be suffering from secretory hypo function which may cause mucositis, rampant dental caries, infections of the mouth and pharynx as well as difficulty in swallowing, speech and taste [10].

MTX has been used for many years, but because of the side effects, there is a continuous search to lessen its toxicity. In MTX treatment a dose-response relation exists, but the optimal dose is individually determined. There are few references light on the effect of a high dose of methotrexate on one of the vital organs of the body which is the submandibular salivary gland. Apoptosis induced may be one of the major causes of the acute injury on the submandibular salivary gland after methotrexate treatment in cancer patients. The complex relation between cell proliferation, differentiation, and apoptosis is a cardinal feature in maintenance of the normal architecture and function of the submandibular gland. Repopulation of tissue is an important feature of the recovery of the chemotherapy - induced injury [11,12]. Ibrahim et al. [12] found that the time for a drug required to reach the maximum

*Corresponding author: Ameera Kamal, Department of Oral Diagnosis, College of Dentistry, Hawler Medical University, Erbil, Kurdistan Region of Iraq, Tel: 009647504882164; E-mail: amera1kam@yahoo.com

Shaheen Ali, Department of Oral Diagnosis, College of Dentistry, Hawler Medical University, Erbil, Kurdistan Region of Iraq; Tel: 009647504483301;E-mail: shahenallany@yahoo.com

Received October 29, 2013; Accepted December 30, 2013; Published January 01,2014

Citation: Al-Refai AS, Khaleel AK, Ali S (2014) The Effect of Green Tea Extract on Submandibular Salivary Gland of Methotrexate Treated Albino Rats: Immunohistochemical Study. J Cytol Histol 5: 212. doi:10.4172/2157-7099.1000212

Copyright: (c) 2014 Al-Refai AS, et al. This is an open-access article distributed under the terms of the Creative Commons Attribution License, which permits unrestricted use, distribution, and reproduction in any medium, provided the original author and source are credited. 
concentration in submandibular saliva was shorter than that in parotid saliva; for this reason the current study was aimed to investigate the potential anticytotoxic effect of green tea extract $(40 \mathrm{mg} / \mathrm{kg} /$ day) on the submandibular glands of Albino rat treated with a high single dose of MTX. As variables to evaluate the grade of damage or protection, we used histological and immunohistochemical investigations to clarify its effect on cell proliferation and apoptosis.

\section{Materials and Methods}

\section{Preparation of the extract}

Daily method of tea making (household preparation) from green tea (Alwazah Swan Brand 100\% pure Nett $225 \mathrm{~g}$ ) was used to prepare aqueous extracts. The aqueous extract was prepared in ratio 1:10 with the consideration of the absorption coefficient of green tea leaves (which is 2). Five grams of dried green tea leaves were grinded to pieces of diameter lower than one $\mathrm{mm}$ were poured with $60 \mathrm{ml}$ of boiling distilled water [13], and time was given for the extraction to cool down and the mixture was filtered first with a fine muslin cloth under pressure and the clear filtrate was dried in a water bath at $40^{\circ} \mathrm{C}$ until a paste was obtained, dissolved in distal water and used at a concentration of 40 $\mathrm{mg} / \mathrm{kg} /$ day [14].

\section{Animals and study design}

Thirty six healthy Albino rats of $250 \pm 25 \mathrm{mg}$ weight obtained from the animal house, College of Medicine, Hawler Medical University, were used for the study and kept under laboratory conditions and housed in a temperature-controlled environment $\left(21-24^{\circ} \mathrm{C}\right)$, maintained on a 12 $\mathrm{hr}$ light/12 hr dark cycle and given free access to food and water. The research project was approved by the Research Ethics Committee at College of Dentistry, Hawler Medical University under protocol.

In the pilot study, twelve animals were used to find the effect of different doses of MTX (Ebewe Pharma Ges, Austria $50 \mathrm{mg} / 5 \mathrm{ml}$ ) on the rat submandibular salivary gland. The animals were divided into four groups (three animals each), they received intraperitoneal injection of MTX: $10 \mathrm{mg} / \mathrm{kg}, 20 \mathrm{mg} / \mathrm{kg}, 40 \mathrm{mg} / \mathrm{kg}$, and $80 \mathrm{mg} / \mathrm{kg}$ body weight respectively. After 48 hours, all the animals were sacrificed by overdose of anesthesia and biopsies from the submandibular glands of the animals were taken, fixed and processed for H\&E.

\section{The results of the pilot study}

Results showed that when there was increase in the dose of MTX there was increase in the cytotoxic effect. After 48 hours, the MTX showed acute effect, the microscopical picture of rat's submandibular gland treated by $10 \mathrm{mg} / \mathrm{kg}$ or $20 \mathrm{mg} / \mathrm{kg}$ of MTX showed areas of hemorrhage and spaces surrounded the duct system. Acinar and duct cells swelling with involution and disfigured lobular structure of some acini, and the granules in acinus cell cytoplasm appear larger than normal (Figures 1A and 1B). But in the submandibular gland of rats treated by $40 \mathrm{mg} / \mathrm{kg}$ of MTX, some acini showing loss of their normal architecture, the lining cells of the acini were indistinct and showed numerous cytoplasmic vacuolations with scattered small and dark pyknotic nuclei of different size, and marked vasodilatation of the blood capillaries. The ducts become dilated with discontinuity of their epithelial lining in some areas with a morphological change in the striated ducts represented by shrinkage of the ductal cells that lead to change of these cells from columnar to cuboidal cells (Figure 1C).

The result of pilot study also showed that the maximum toxic effects of the drug were seen in the submandibular glands of rats treated by 80 $\mathrm{mg} / \mathrm{kg}$ of MTX, as seen in the result (Figure 3). For this reason the other twenty four animals were randomly divided into four groups (six animals/cage):

Group 1: Vehicle treated control group: Distilled water was administered orally two times daily by intragastric gavage needle for five days, and physiological saline $(0.9 \% \mathrm{NaCl})$ was administered intraperitoneally instead of MTX after 72 hour from the beginning of the experiment.

Group 2: Green tea extract treated control group: The extract of green tea $(20 \mathrm{mg} / \mathrm{kg})$ was administered orally two times daily (total $40 \mathrm{mg} / \mathrm{kg} /$ day) by intragastric gavage needle for five days, and physiological saline $(0.9 \% \mathrm{NaCl})$ was administered intraperitoneally instead of MTX after 72 hour from the beginning of the experiment.

Group 3: MTX (80 mg/kg)-non green tea extract, treated group. The distilled water was administered orally two times daily for five days, and the animals received intraperitoneal injection of MTX after 72 hour from the beginning of the experiment.

Group 4: MTX $(80 \mathrm{mg} / \mathrm{kg})$ and green tea extract, treated group. The green tea extract $(20 \mathrm{mg} / \mathrm{kg})$ was administered orally two times daily throughout the five days of the experiment, but the intraperitoneal injection of MTX was done after 72 hour from the beginning of the experiment.
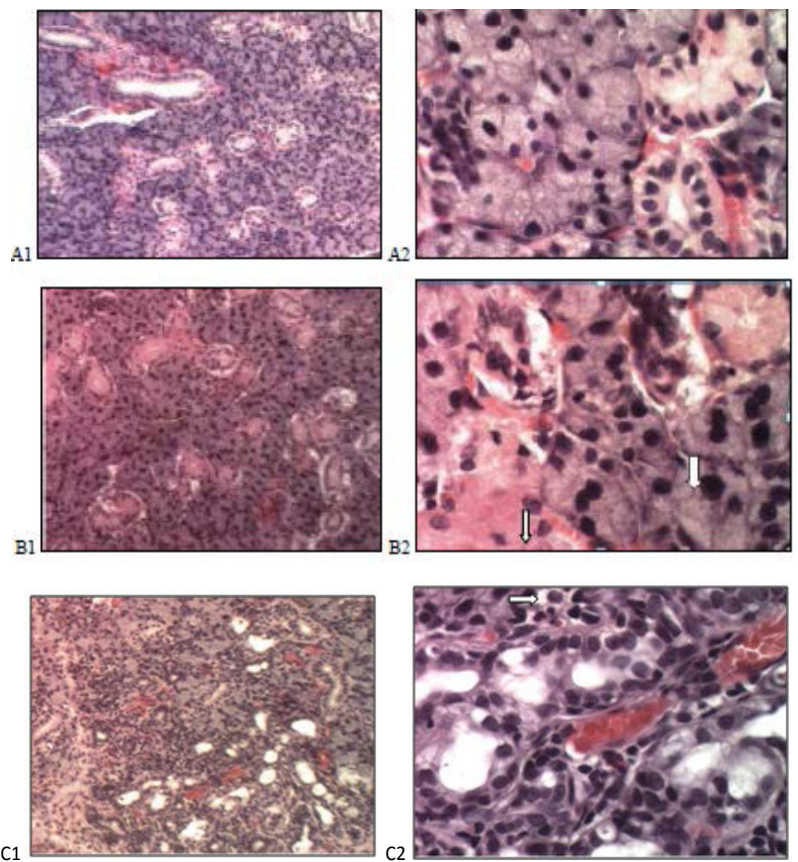

Figure 1: (A) A photomicrograph of the submandibular gland of rat treated by $10 \mathrm{mg} / \mathrm{kg}$ methotrexate, showing areas of hemorrhage suround the straiated ducts specialy the large one $(A 1, H \& E \times 100 ; A 2, H \& E \times 400)$. (B) Submandibular gland of rat treated by $20 \mathrm{mg} / \mathrm{kg}$ methotrexate, showing stasis of acini secretions within the ducts $(B 1, H \& E \times 100)$. Some times seepage of the duct secretion outside the duct causing shrinkage of its epithelium. Acinar cells swelling which contain large granules in their cytoplasm are also seen(large arrow) with enlargement of the granular convoluted tubules(smal arrow) (B2, H\&E ×400). (C) Submandibular gland of rat treated by $40 \mathrm{mg} / \mathrm{kg}$ methotrexate, the acini showing loss of their normal architecture $(\mathrm{C} 1, \mathrm{H} \& \mathrm{E}$ $\times 100$ ). Cytoplasmic vacuolation of some cells (arrow) which showing different cell sizes and nuclear sizes with marked congestion of the blood capillaries The ducts become highly dilated with discontinuity of their epithelial lining in some areas (C2, H\&E ×400). 
In the fifth day of the experiment, the animals were sacrificed by overdose of anesthesia and biopsies from the submandibular glands of the animals were taken. Samples were then fixed in neutral buffered $10 \%$ formalin, processed for H\&E, Masson's trichrome [15], PAS staining [15] and for immunohistochemical analysis using Bcl-2 and Ki-67 immunolabeling.

\section{Immunohistochemical staining}

A recognized indicator of cell mitotic activity is $\mathrm{Ki}-67$, an increase in Ki-67 expression is indicative of increased cell mitotic activity and proliferation. Ki-67 monoclonal antibodies detect a nuclear antigen expressed exclusively at the level of cells in the proliferation phase (phases G1, S, G2 and mitoses), but not in the G0 phase. Therefore, Ki-67 antibodies allow for the immunohistochemical determination of the tissue growth fraction [16]. Bcl-2 is important effecter gene during the apoptosis process and has been reported to prolong the survival of cells by specifically inhibiting apoptosis. The balance between mitotic activity and apoptosis is thought to regulate normal development [17].

In the study, immunostaining for Ki-67 and Bcl-2 was performed using monoclonal Mouse Anti-Human Ki-67 Antigen, Clone MIB1, and Code No. M 7240 staining system, and a monoclonal Mouse Anti-Human BcL-2 Oncoprotien Clone 124 Code No 1587 ready to use $\mathrm{N}$-series primary antibody, for use with Dako EnVision ${ }^{\text {Tx }}$, EnVision ${ }^{\text {Tx }}$ double staining and LASAB ${ }^{\text {sa }} 2$ systems. The staining procedure sections of the instructions included with each detection system were followed. Positive and negative controls were run simultaneously with biopsy specimen.

Positive cells expressing Ki-67 were identified by a brown precipitate in the nucleus except in mitotic cells, where the chromosomes and the cytoplasm are labeled, while Bcl-2 was demonstrated brown cytoplasmic staining. To ensure the objectivity of the analysis, the evaluation was carried out by two independent observers. Five sections were randomly chosen for each animal. Approximately 1000 cells from cell population were counted by two observers at a magnification of 400x (Olympus, Japan) and the percentages of Ki-67 and Bcl-2 positive cells were calculated. The level of Ki-67 and Bcl-2 expression was evaluated according to the scoring system of Seleit et al. [18]. The application of this system gives a score ranging from 0 to 3 for both degree of positivity: percentage of positively stained cells [(absent: <1\%), (mild: 1-10\%), (moderate: $10-50 \%)$, (strong: $>50 \%)$ ]. The ANOVA test was used to compare the results of Ki-67 and Bcl-2 staining. Level of significance was set as $\mathrm{p} \leq 0.01$.

\section{Results}

\section{Anatomical and microscopical features of rat's submandibular salivary gland in the control groups}

Careful removal of the skin of the neck and the face reveal the presence of the salivary glands. Rat sublingual glands are located together with the submandibular glands on the sides of the neck between the submandibular lymph nodes and the sternum. Both glands were included within a common connective tissue capsule. They were separated from each other by fine connective tissue septa. The submandibular glands in the control groups were composed of crowded serous acini only and not more types that in most mammals (Figure 2), there are no mucous or serous demilunes, the serous acini had narrow lumen and lined by pyramidal cells with pale basophilic granular cytoplasm and basal rounded nuclei. The duct system consists of intercalated duct, granular convoluted tubules, striated and excretory ducts. No differences in the microscopical pictures of rat's submandibular glands of both control groups were seen.

\section{The submandibular salivary gland in the methotrexate (80 $\mathrm{mg} / \mathrm{kg}$ )-non green tea extract, treated group}

Microscopically, severe focal areas of acini destruction can be seen especially near the large ducts, swelling and increase in the sizes of some acini were also seen. The serous cells showed deeply stained atrophied nuclei, different cell sizes (anisocytosis), and different nuclear sizes (anisonucleosis). Giant nuclei and marked congestion of the blood capillaries were also seen. The cytoplasmic vacuolation in acinar and ductal cells were increased with destruction in some duct walls (Figure $3)$.

\section{The submandibular salivary gland in the methotrexate $(80$} $\mathrm{mg} / \mathrm{kg}$ ) and green tea extract, treated group

Microscopical picture revealed marked improvement in cells of acini as well as cells of ducts lining, and the acini relatively preserved their shape. The numbers of vacuoles decreased and well formed striated ducts were also detected. They restored their basal striations and had intact epithelial lining. The intercalated ducts were noticed in between the acini. The granular convoluted tubules were lined by simple columnar epithelium with eosinophilic cytoplasm and basal rounded nuclei. Blood vessels were seen around these ducts, no congestion or areas of hemorrhage were seen (Figure 4).
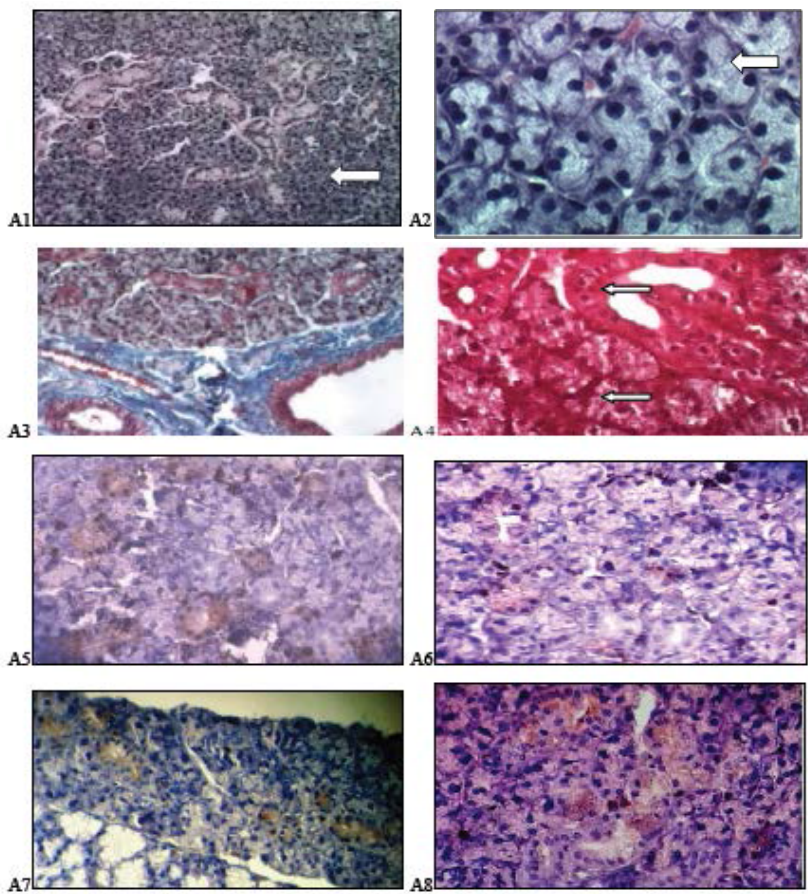

Figure 2: Photomicrographs of rat submandibular gland of control groups showing regular structured acini (arrows) (A1, H\&E × 100; A2, H\&E ×400). The collagen fibers are distributed in the stroma between the acini and duct (A3, Trichrome $\times 100$ ). Strong positive PAS reaction in striated duct (upper arrow) and acini (lower arrow) which is observed more at their basement membrane (A4, PAS $\times 400)$. Moderate $\mathrm{Ki}-67$ immuno reactivity in nuclei of cells of ducts and some acini in the first and second group respectively (A5, A6), and moderate cytoplasmic reaction to $\mathrm{Bcl}-2$ mostly seen in association with duct's cells in the first and second group respectively (A7, A8), (immunohistochemistry $\times 400$ ). 

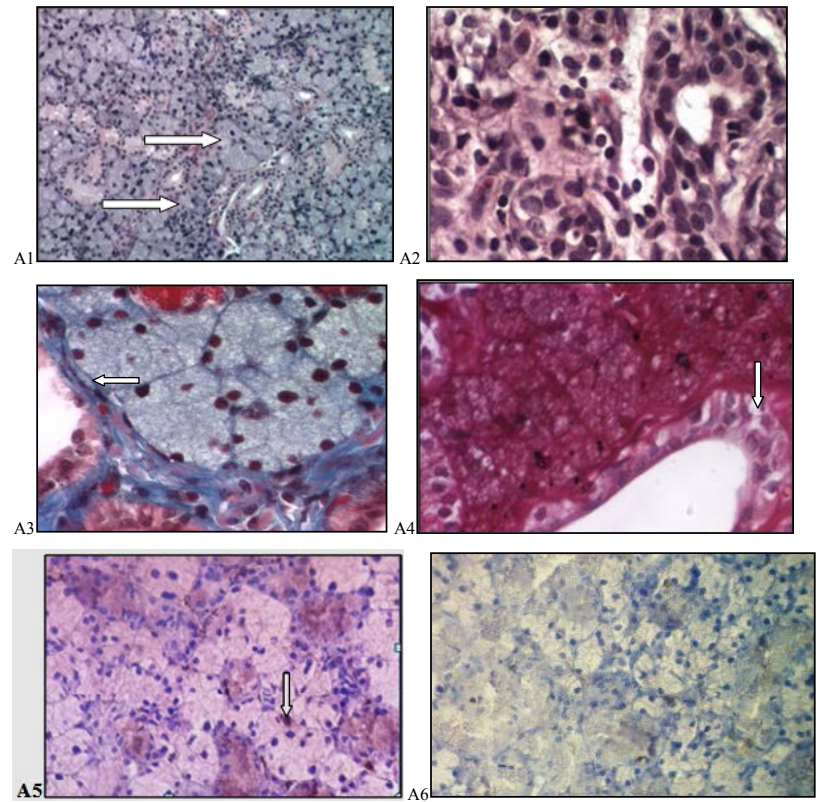

Figure 3: A photomicrograph of a section in submandibular gland of rat treated by $80 \mathrm{mg} / \mathrm{kg}$ methotrexate, showing swelling (upper arrow) and disarrangement of some acini (lower arrow) (A1, H\&E ×100). Severe cellular changes with irregular configuration of the acini and detached acinar cells, some cells showed increased nuclear cytoplasmic ratio, hyper chromatic nuclei and extreme anisonucleosis, interacinar oedema and signs of intracellular vaculation $(A 2, H \& E \times 400)$. The collagen fibers seen distributed in the stroma in between the acini and duct, with destruction in duct wall, (arrow) (A3, Trichrome $\times 400$ ). PAS - stained tissue showing duct cells with increase in nuclear cytoplasmic ratio, dense nuclei and lost cytoplasm (arrow), acinic cells shows vaculation with loss of some nuclei (A4, PAS $\times 400$ ). Mild Ki- 67 mmuno reactivity(arrow) in nuclei of few cells (A5) and negative cytoplasmic reaction to $\mathrm{Bcl}-2(\mathrm{~A} 6)$, (immunohistochemistry $\times 400)$.

Histopathological examination of the submandibular glands that were excised from the rats in all groups showed no evidence of collagen fiber breakdown, fibrosis, or an increase in inflammatory cells. A PAS positive reaction produces an intense magenta color, mainly indicating the presence of glycoprotein and glycogen. Only sections in the submandibular salivary gland of control groups albino rat's and in the methotrexate and green tea extract treated group showed strong positive PAS reaction, appear in both ducts and acini which is observed more at their basement membrane (Figures 2 and 4 ).

\section{Immunohistochemical results}

The Ki-67 immunostaining results in the methotrexate and green tea extract treated group showed mild positive Ki-67 immunoreactions in the nuclei of acinar and ductal cells. This may suggest both the undamaged parenchymal and ductal cells attempts for regeneration and proliferation (Figure 4A5). There was a statistically no significant difference present $(\mathrm{P}>0.01)$ between the group1 $(22.166 \pm 2.483)$ and $2(21.692 \pm 1.658)$ regarding the Ki-67 immune expression. But there was a statistically significant difference $(\mathrm{P}<0.01)$ present between group 1 or 2 and the other two experimental groups in terms of the rate of proliferation, but a statistically no significant difference $(\mathrm{P}>0.01)$ was observed between group 3(1.246 \pm 0.624$)$ and 4(1.966 \pm 0.628$)$.

The Bcl-2 immunostaining results in the methotrexate and green tea extract treated group showed moderate positive Bcl-2 immunoreactions in the cytoplasm of most ductal cells (Figure 4A6). There was a statistically no significant difference present $(\mathrm{P}>0.05)$ between group1 $(17.31 \pm 3.538)$ and $2(18.969 \pm 2.542)$ regarding the Bcl-2 immune expression. But there was a statistically significant difference present $(\mathrm{P}<0.01)$ between group $3(0.466 \pm 0.320)$ and the other groups in terms of the rate of anti apoptosis, but a statistically no significant difference $(\mathrm{P}>0.01)$ was observed between group 1 or 2 and group $4(19.75 \pm 4.239)$.

\section{Discussion}

The result showed that the rat's submandibular gland contain serous acini only, this results disagree with that of Ahmad [19] in which they found that it was mixed salivary gland, but agree with the result of Miclaus et al. [20]. They reported that the acini of submandibular glands of rats had the feature of serous acini, similar but not identical with those from parotid gland. In addition of excretory channels present in mammalian salivary glands, in submandibular gland of the rats there's one more type of channels, named granular channels. Cells from walls of granular channels contain numerous polymorphous intra cytoplasmatic granulations which suggest that they have an intense secretory activity. Authors added that granulations from cytoplasm of cells from granular channels are different from those of the acini structure and their secretion is muco-proteic. By mixing serous secretions of acini with that muco-proteic of the granular channels cells, resulted in a mixed final secretion which make us to consider submandibular gland of the rat a mixed particular gland.

The salivary glands have become a useful investigative tool for the study of basic problems in pharmacology [21]. Despite the low mitotic rate, the salivary gland tissue loses its function regularly with significant reduction of saliva production after exposure to
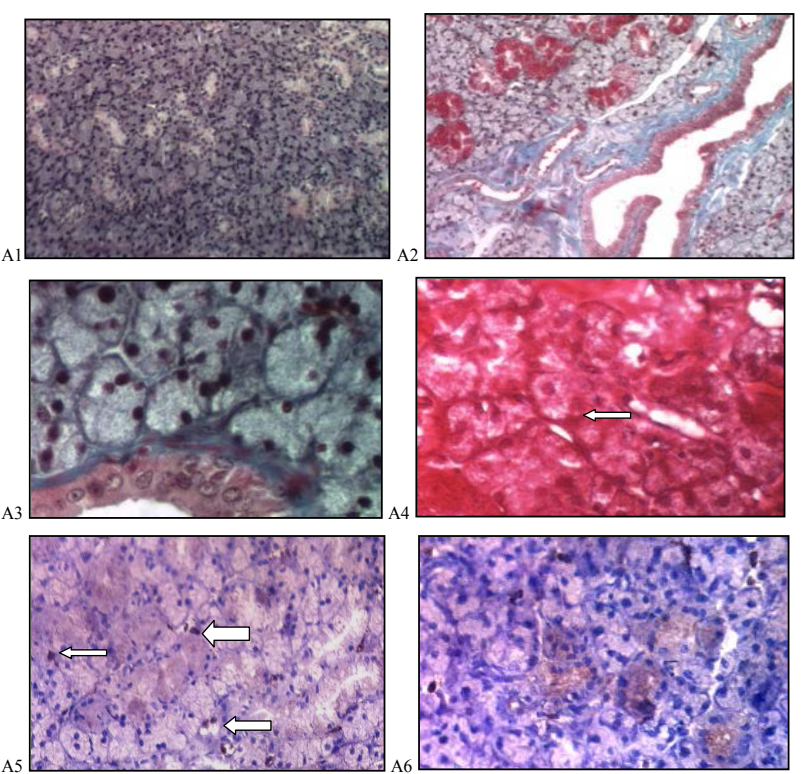

Figure 4: A photomicrograph of a section in submandibular gland of the methotrexate and green tea extract treated group showing well formed acin and duct lining $(A 1, H \& E \times 100)$. The collagen fibers are distributed in the stroma between the acini and ducts, intact multiple granular convoluted tubules and intact duct lining are seen, no congested blood vessels were found (A2 Trichrome $\times 100, A 3$, Trichrome $\times 400$ ). Strong positive PAS reaction in the ducts and acini with more concentration at their basement membrane, (arrow) (A4, PAS $\times 400$ ). Mild $\mathrm{Ki}-67$ immuno reactivity in nuclei (arrows) of some acinar cells (A5) and moderate positive cytoplasmic reaction in duct's cells to $\mathrm{Bcl}-2(\mathrm{~A} 6)$, (immunohistochemistry $\times 400$ ). 
chemotherapeutic doses like methotrexate, a folic acid antagonist [22]. In the present study, one dose of injected methotrexate had adversely affected the histological structure of the rat submandibular glands, this could be due to suppression and/or disruption of protein synthesis through depletion of foliate co-factors, this can lead to formation of cytolysosome, may be an evidence of the distinctive process of apoptosis, the apoptotic bodies which are found in small numbers in normal tissues are greatly increased in tissues which have been subjected to chemotherapy [1]. Damaging of the salivary gland (acinar and ductal cell vacuolization, apoptosis in the acinar cells with pyknosis in the nuclei) following methotrexate treatment might be also related to the free radical damaging effect. These free radicals released during the intracellular metabolism of MTX, which interacts with the cell membrane, causing membrane lysis and release of major scavenger enzymes (glutathione based enzymes) such as (glucose 6-phosphate dehydrogenase and glutathione reductase) into the serum. This affects the physiological level of this antioxidant enzyme in serum and gives an indication of an adverse effect of MTX on cellular integrity [23]. But Wolff et al. [24] found that 18 hour after $(15 \mathrm{mg} / \mathrm{kg}$, i.p.) MTX administration no salivary effects could be detected consistently and this dose do not exert an acute cytotoxic effect on tissue with a slow turnover rate like the salivary glands.

The result also showed that the severity of pathological changes increased as chemotherapeutic doses increased. This comes in agreement with the result of Ozel et al. (25).The enlargement of the acini might be due to dysfunction of the gland and disturbed salivary secretion leading to accumulation of the salivary secretion in the acini following by its swelling. Some ducts showed dilation with retaining secretion in their lumen, this dilation of ducts suggested the pathological effect of MTX on myoepithelial cells embracing them with failure of expelling the secretion into the oral cavity as a result of glandular dysfunction leading to xerostomia. Mahmoud et al. [25,26] found that the rabbits when injected with ( $15 \mathrm{mg} / \mathrm{kg}$, i.p.) MTX for two weeks, the same result appears.

The extent of damage in the salivary gland tissue of rats treated by high dose of MTX depend on the size of the affected duct, this comes in agreement with the results of Al-Moula et al. [1]. The accumulation of secretory material within the cytoplasm of acinar cells led to degenerative changes in the acinar cells that frequently resulted in cell death and replacement of secretory cells by connective tissue elements. Granular changes were observed in the cytoplasm of acinar cells in the submandibular gland of the rats in methotrexate treated group. The secretory granules in the serous cells include many proteolytic enzymes and heavy metals. This condensation in the granules indicates non-specific cytoplasmic degeneration and shows reversible cellular damage [25].

To our knowledge no investigation using green extract to fight the cytotoxic effect of a high toxic dose of MTX on rat submandibular salivary gland has been performed. In the present study, the combined treatment of MTX and green tea extract ameliorated the histological changes in salivary gland tissue induced by MTX alone. The antioxidant properties, reactive oxygen species scavenging, and cell function modulation of flavonoids could account for the large part of pharmacological activity of green tea [27].

The data presented in our study showed that green tea cause non significant increase the expression of Ki-67, and significant increase in the antiapoptotic activity in the glands in relation with the methotrexate group. Previous report found that EGCG significantly inhibited TNF- $\alpha$ induced apoptosis in human salivary gland acinar cells in vitro. This inhibitory effect on apoptosis could be due to modulation of MAPK signal to interrupt an apoptotic signal [28]. So with the administration of green tea extract that protects salivary gland from apoptosis by increasing significantly the anti apoptotic activity, it can be used as a criterion and can be used as, a novel approach to decrease the cytotoxicity of methotrexate on submandibular gland. As suggestion, the same study is needed to be repeated on human. Sawyer and Ratain [29] advocate the use of body surface area (BSA) as a factor when converting a dose for translation from animals to humans.

\section{Conclusion}

The beneficial effect of green tea aqueous extract at a concentration of $40 \mathrm{mg} / \mathrm{kg} /$ day against MTX induced cytotoxicity in the submandibular salivary glands of rats stem from its antiapoptotic effect and therefore can be used as a protective natural product to the salivary glands in individuals undergoing cancer therapy.

\section{References}

1. Al-Moula AD, Al-Mashhadane F, Mammdoh JK9 (2012) Effects of 6-mercaptopurine on salivary glands in rabbit. Al-Rafidain Dent J 12: 66-273.

2. Klareskog L, Vander Heijde D, de Jager JP, Gough A, Kalden J, et al. (2004) Therapeutic effects of the combination of etanerceept and methotrexate compared with each treatment alone in patients with rheumatoid arthritis: Double blind randomized controlled trial. Lancet 363: 675-681.

3. Harten $P(2005)$ [Reducing toxicity of methotrexate with folic acid]. Z Rheumato 64: 353-358.

4. Sener G, Ekşioğlu-Demiralp E, Cetiner M, Ercan F, Sirvanci S, et al. (2006) L-Carnitine ameliorates methotrexate-induced oxidative organ injury and inhibits leukocyte death. Cell Biol Toxicol 22: 47-60.

5. Yapar K, Cavuşoğlu K, Oruç E, Yalçin E (2009) Protective effect of royal jelly and green tea extracts effect against cisplatin-induced nephrotoxicity in mice: a comparative study. J Med Food 12: 1136-1142.

6. Braicu C, Ladomery MR, Chedea VS, Irimie A, Berindan-Neagoe I (2013) The relationship between the structure and biological actions of green tea catechins. Food Chem 141: 3282-3289.

7. Bajerska J, Wozniewicz M, Jeszka J, Drzymala-Czyz S, Walkowiak J (2011) Green tea aqueous extract reduces visceral fat and decreases protein availability in rats fed with a high-fat diet. Nutr Res 31: 157-164.

8. Chandra AK, Choudhury SR, De N, Sarkar M (2011) Effect of green tea (Camellia sinensis L.) extract on morphological and functional changes in adult male gonads of albino rats. Indian J Exp Biol 49: 689-697.

9. Gillespie K, Kodani I, Dickinson DP, Ogbureke KU, Camba AM, et al. (2008) Effects of oral consumption of the green tea polyphenol EGCG in a murine model for human Sjogren's syndrome, an autoimmune disease. Life Sci 83 581-588.

10. Dodds MW, Johnson DA, Yeh CK (2005): Health benefits of saliva: a review. J Dent 33: 223-233.

11. Bralic M, Muhvic-Urek M, Stemberga V, Golemac M, Jurkovic S, et al. (2005) Cell death and cell proliferation in mouse submandibular gland during early post-irradiation phase. Acta Med Okayama 59: 153-159.

12. Ibrahim SH, Soliman ME, Yehia NM (2004) Effect of ciprofloxacin on the submandibular salivary gland of adult male albino rat, A light and electron microscope study. The Egyptian journal of Histology 27: 339-354.

13. Armoskaite $V$, Ramanauskiene K, Maruska A (2011) The analysis of quality and antioxidant activity of green tea extracts. Journal of Medicinal Plants Research 5: 811-816.

14. Gawish AM, Ramadan S, Hassan AM, Issa AM (2010) Morphometrical Histopathological, and Cytogenetical Ameliorating Effects of Green Tea Extract on Nicotine Toxicity of the Testis of Rats. J Cytol Histol 1: 105.

15. Bancrof J, Gamble A (2002) Theory and Practice of Histological Techniques. (5thedn), Churchil, Livingstone, NewYork and London, USA, 165-180.

16. Lazăr D, Tăban S, Sporea I, Dema A, Cornianu M, et al. (2010) Ki-67 expression in gastric cancer. Results from a prospective study with long-term follow-up. Rom J Morphol Embryol 51: 655-661. 
Citation: Al-Refai AS, Khaleel AK, Ali S (2014) The Effect of Green Tea Extract on Submandibular Salivary Gland of Methotrexate Treated Albino Rats: Immunohistochemical Study. J Cytol Histol 5: 212. doi:10.4172/2157-7099.1000212

Page 6 of 6

17. Ribeiro DA, Salvadori DM, Marques ME (2005) Abnormal expression of bcl2 and bax in rat tongue mucosa during the development of squamous cell carcinoma induced by 4-nitroquinoline 1-oxide. Int J Exp Pathol 86: 375-381.

18. Seleit IA, Asaad N, Maree A, Abdel Wahed M (2010) Immunohistochemical expression of $\mathrm{p} 53$ and $\mathrm{Ki}-67$ in cutaneous lupus erythematosus. J Egypt Women Dermatol Soc 7: 5-15.

19. Ahmad SM (2007) Histological and immunohistochemical study of the submandibular salivary gland in experimentally induced diabetes mellitus in adult male albino rats. MSc Thesis, Zagazig University.

20. Miclaus V, Oana L, Ober C, Rus V, Pestean C (2009) Observations concerning features of submandibular gland secretion in rats. Lucrari Stiinlifice Medicina Veterinara 9: 382-386.

21. Rafah A, Alham DH, Tahani A (2006) Effect of natural apple cider vinegar on morphometric changes of salivary glands in hydroxyl urea treated mice. J Edu Sci 18: 62-77.

22. Jensen SB, Pedersen AM, Reibel J, Nauntofte B (2003) Xerostomia and hypofunction of salivary glands in cancer therapy. Support Care Cancer 11: 207-225.

23. Hus PC, Hour TC, Liao YF, Hun YC, Chang WH, et al. (2006) Increasing ornithine decarboxylase activity is another way of prolactin preventing methotrexate induced apoptosis: Crosstalk between ODC and Bcl-2. Apoptosis 11: 389-399.
24. Wolff A, Moreira JE, Marmary Y, Fox PC (1989) Lack of acute effects of methotrexate on rat parotid salivary gland function. Arch Oral Biol 34: 109-115.

25. Ozel O, Aycicek A, Kenar F, Aktepe F, Sargin R, et al. (2010) Histopathologic changes in the rabbit submandibular gland after 5-fluorouracil chemotherapy. Turk J Med Sci 40: 213-220.

26. Mahmoud EF, Mahmoud MF, Abd Al Haleem MA (2012) Royal jelly ameliorates oxidative stress and tissue injury in submandibular salivary gland of methotrexate treated rabbits: Immunohistochemical study. Journal of American Science 8: 501-508.

27. Hafez SE (2006) Using green tea in controlling structural disorders of radiation in some organs in male albino rats. J Drug Res 27: 90-97.

28. Hus S, Dickinson DP, Qin H, Broke J, Ogbureke K, et al. (2007) Green tea polyphenols reduce autoimmune symptoms in a murine model for human Sjogren's syndrome and protect human salivary acinar cells from TNF-alpha induced cytotoxicity. Autoimmunity 40: 138-147.

29. Sawyer M, Ratain MJ (2001) Body surface area as a determinant of pharmacokinetics and drug dosing. Invest New Drugs 19: 171-177. 